\title{
Analysis of segregation patterns in Machado-Joseph disease pedigrees
}

\author{
Conceição Bettencourt • Cristina Santos • \\ Teresa Kay · João Vasconcelos · Manuela Lima
}

Received: 18 April 2008/Accepted: 16 July 2008/Published online: 9 August 2008

(C) The Japan Society of Human Genetics and Springer 2008

\begin{abstract}
Machado-Joseph disease (MJD), also known as spinocerebellar ataxia type 3 (SCA3), is an autosomal dominant neurodegenerative disorder of late onset, which is considered the most common form of SCA worldwide. The main goal of this study was to investigate the presence of segregation ratio distortion (SRD) during transmissions of ATXN3 alleles by MJD patients, evaluating the putative role of SRD in the epidemiological representation of the disease. Sixty-two complete sibships, each with one clinically affected parent, totalling 330 transmissions were selected according to defined criteria and used for segregation analysis. Onset data from MJD patients with Azorean origin was used for residual risk estimates according to different ages. Residual risk values were applied to unaffected offspring to calculate the probability of inheriting the expanded allele. The proportion of
\end{abstract}

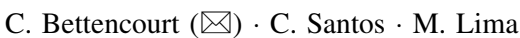

Center of Research in Natural Resources (CIRN)

and Department of Biology, University of the Azores,

Rua Mãe de Deus, Apartado 1422, 9501-801 Ponta Delgada,

Azores, Portugal

e-mail: mcbettencourt@uac.pt

C. Santos

Biological Anthropology Unit, Department BABVE,

Faculty of Biosciences, Autonomous University of Barcelona,

Bellaterra, Barcelona, Spain

T. Kay

Department of Clinical Genetics,

Hospital of D. Estefania, Lisbon, Portugal

J. Vasconcelos

Department of Neurology,

Hospital of Divino Espirito Santo,

Ponta Delgada, Portugal offspring that received the expanded or the normal allele from the affected parent was calculated to determine the presence of SRD during transmissions of ATXN3 alleles by MJD patients. Segregation of ATXN3 alleles was in accordance with the expected Mendelian proportions $\left(\chi^{2}=0.982, P=0.322\right)$. However, there was a tendency favouring the transmission of the normal alleles. Thus, SRD is not a potential mechanism on the basis of MJD epidemiological representation.

Keywords Mendelian transmission - MJD - Prevalence . Residual risk $\cdot \mathrm{SCA} 3$

\section{Introduction}

Machado-Joseph disease (MJD) (MIM 109150), also known as spinocerebellar ataxia type 3 (SCA3), is an autosomal dominant neurodegenerative disorder of late onset that involves the cerebellar, ocular motor, pyramidal, extrapyramidal and peripheral motor systems. Mean age at onset is 40.2 years, with extremes of 7 and 70 years, and mean survival time being 20 years (Coutinho 1992). The clinical heterogeneity presented by MJD patients led to their classification into three clinical types, which can be occasionally present in a single family, with cerebellar ataxia and ophthalmoplegia being common to all of them (Coutinho and Andrade 1978).

The MJD locus was mapped to 14q32.1 (Takiyama et al. 1993). An expansion of a triplet repeat with a CAG motif at exon 10 of the ATXN3 gene was identified as the causative mutation for this disorder (Kawaguchi et al. 1994; Ichikawa et al. 2001). The wild-type alleles present between 12 and 44 CAG units, whereas the expanded alleles contain between 61 and 87 CAG repeats (Maciel et al. 2001). 
Molecular testing by direct detection of the mutation is available for MJD, allowing predictive testing and prenatal (Sequeiros et al. 1998) and preimplantation genetic diagnosis (Drüsedau et al. 2004). As the estimated penetrance of the gene is almost complete ( 98\%) (Sequeiros 1993), a result of "carrier" implies that the individual will become affected. Each affected individual (assumed to be heterozygous) has an a priori risk of $50 \%$ of transmitting the disease allele to each offspring. Individuals at risk mainly base their future expectations upon this a priori risk. However, MJD penetrance displays an age-dependent pattern, implying that the probability of being a mutation carrier diminishes with age of the asymptomatic individuals (Sequeiros 1996). Thus, the a posterior risk or residual risk status (RRS) may differ considerably depending on the age of the individual.

SCAs are considered rare disorders, as their prevalence has been estimated to be $\sim 3$ in 100,000 . As a member of the SCA group, MJD is considered the most common form of SCA worldwide (Cagnoli et al. 2006). The Azores, a group of Portuguese Islands to where the first descriptions of MJD trace (Nakano et al. 1972; Woods and Schaumburg 1972), remain the most important cluster of this disease. To date, 32 extended MJD families with origins in Flores, S. Miguel, Terceira and Graciosa islands, were identified (MJD prevalence by January $2008 \sim 1: 3,472$ ). In Flores Island, although the prevalence values have been progressively decreasing in the last 10 years, ranging from 1:103 (Lima et al. 1998) to 1:239 (by January 2008), MJD still reaches its highest worldwide value, constituting a public health problem.

Several mechanisms may explain the relatively high representation of MJD worldwide. The hypothesis of a higher fitness in Portuguese MJD families has been investigated, but no differences were found between cases and controls (Lima 1996; Abade et al. 2000; Santos et al. 2000; Lima et al. 2001). An alternative hypothesis, which may also explain the high representation of the disease, could be the presence of segregation ratio distortion (SRD) in favour of the expanded alleles. Results concerning SRD in previous studies, based on different methodologies (Ikeuchi et al. 1996; Riess et al. 1997; Takiyama et al. 1997; Iughetti et al. 1998; Grewal et al. 1999), are not consensual and therefore do not elucidate this possibility.

The availability of an extended genealogical database for the Azorean MJD families, associated with the thorough follow-up of patients, as well as previous work on SRD using normal families (Bettencourt et al. 2008), provided the background to conduct our study. The aim of this study was to analyse the segregation patterns of ATXN3 alleles to determine whether SRD in favour of expanded alleles could constitute one of the mechanisms responsible for the maintenance of the high levels of MJD prevalence.

\section{Subjects and methods}

\section{Risk assessment}

Age at onset for a total of 176 patients from the Azores was used to determine the probability of detectable gene expression in this population. Given the fact that a higher mean age at onset was described for patients from Flores Island (Coutinho 1992; Bettencourt et al. 2005), data for 78 patients with origin in this island was used separately to calculate the probability of heterozygosity (RRS) for at-risk individuals from Flores. For risk assessment purposes, the MJD gene (whose penetrance has been estimated to be $98 \%$ ) was considered fully penetrant. Given the age-dependent penetrance, Bayesian analyses were used, according to Young (2007), to calculate the RRS for individuals who are still asymptomatic at different ages.

Segregation analysis

Detailed clinical and demographic information from 32 extended Azorean MJD families (which comprise $~ 900$ sibships) was compiled by our group. A sample of 330 offspring of MJD patients (62 sibships) belonging to 18 extended families originating from Flores Island was selected for this work. Sibship selection was made according to the following criteria: (a) complete sibship of offspring is known, (b) all offspring were born between 1892 and 1965 (to warrant that by December of 2007, those individuals would be $>42$ years old, which corresponds to the average MJD onset), (c) known disease status by clinical observation (affected/not affected at the time of the study or at the time at death) according to criteria defined by Coutinho and Andrade (1978), and (d) known age at December 2007 and/or age at death.

In attributing the probability of inheriting the expanded ATXN3 allele, a probability of 1 was given to individuals who presented the disease phenotype (116 individuals). For individuals who were still asymptomatic by December 2007 (168 individuals) or at time of death (162 individuals), the age-dependent RRS assessed above was attributed to the correspondent ages. The formula [1 probability of inheriting the expanded allele] was used to calculate the probability of inheriting the normal ATXN3 allele. The sum of those probabilities was used to obtain the proportions of transmission of expanded and normal alleles, respectively.

The $\chi^{2}$ goodness-of-fit test was used to compare proportions of transmission of expanded and normal alleles, considering the expected segregation ratio of 1:1. Statistical analyses were performed using SPSS 15.0 (SPSS Inc. 2006). 


\section{Results}

Risk assessment

For the total Azorean series of MJD patients (176 individuals), mean age at onset was $40.69 \pm 0.95$ [standard error (SE)] years, with extremes of 5 and 70 years. For the Flores series, the mean age at onset was $42.53 \pm 1.65$ (SE) years, which was significantly higher (two-tailed MannWhitney test, $Z=-2.011, P=0.044)$ than that obtained when excluding Flores patients from the total series $[39.23 \pm 1.09(\mathrm{SE})]$.

The probability of detectable gene expression (Table 1) older than 25 years was lower when departing from onset data of Flores series than that obtained when using onset data of the total Azorean series of patients or even of previously published data (Sequeiros 1996). This fact was translated into an increased RRS for later ages in the Flores series. Therefore, probability computations using series of patients with compatible origins are essential for proper assessment of RRS, which could be useful for family members who choose not to be tested or want to know more about their RRS in a pretest situation. Moreover, as RRS values differ depending on the series of patients used for calculations, segregation analysis was performed using RRS obtained from the Flores series.

Table 1 Age-dependent risk for clinically unaffected individuals with an a priori risk of $50 \%$ of developing Machado-Joseph disease

\begin{tabular}{lllll}
\hline $\begin{array}{l}\text { Age } \\
\text { (years) }\end{array}$ & $\begin{array}{l}\text { Azorean series } \\
(n=176 \text { patients })\end{array}$ & & $\begin{array}{l}\text { Flores series } \\
(n=78 \text { patients })\end{array}$ \\
\cline { 2 - 3 } \cline { 5 - 5 } & $\begin{array}{l}\text { Probability } \\
\text { of detectable } \\
\text { gene } \\
\text { expression }\end{array}$ & $\begin{array}{l}\text { Probability of } \\
\text { heterozygous } \\
\text { if unaffected } \\
\text { (RRS) }\end{array}$ & $\begin{array}{l}\text { Probability } \\
\text { of detectable } \\
\text { gene } \\
\text { expression }\end{array}$ & $\begin{array}{l}\text { Probability of } \\
\text { heterozygous } \\
\text { if unaffected } \\
\text { (RRS) }\end{array}$ \\
\hline 5 & 0.01 & 0.50 & 0.01 & 0.50 \\
10 & 0.02 & 0.50 & 0.04 & 0.49 \\
15 & 0.02 & 0.49 & 0.05 & 0.49 \\
20 & 0.03 & 0.49 & 0.06 & 0.48 \\
25 & 0.10 & 0.47 & 0.10 & 0.47 \\
30 & 0.22 & 0.44 & 0.18 & 0.45 \\
35 & 0.38 & 0.38 & 0.33 & 0.40 \\
40 & 0.53 & 0.32 & 0.46 & 0.35 \\
45 & 0.64 & 0.26 & 0.56 & 0.30 \\
50 & 0.80 & 0.17 & 0.71 & 0.23 \\
55 & 0.86 & 0.12 & 0.78 & 0.18 \\
60 & 0.96 & 0.04 & 0.95 & 0.05 \\
65 & 0.97 & 0.03 & 0.95 & 0.05 \\
70 & 1.00 & $\sim 0$ & 1.00 & $\sim 0$ \\
\hline
\end{tabular}

Segregation analysis

Segregation analysis showed no significant deviation from the mendelian 1:1 assumption (Table 2). However, there was a tendency in favour of transmission of normal alleles ( $\sim 53 \%)$, which was more marked in the case of maternal transmission $(\sim 56 \%)$.

\section{Discussion}

In MJD, age at onset can display important differences between series of patients, as previously reported (Coutinho 1992; Bettencourt et al. 2005) and confirmed by our results. Therefore, it is important to consider such variation in the assessment and attribution of RRS in the context of genetic counselling (GC).

Research previously developed concerning the thematic of segregation patterns of the ATXN3 gene by MJD patients produced conflicting results, not clarifying whether SRD could be one of the mechanisms responsible for the maintenance of high levels of MJD prevalence worldwide. In agreement with our results, Grewal et al. (1999), using a single-sperm analysis approach, found no SRD but observed a tendency in favour of the transmission of normal alleles (53.5\% normal: $46.5 \%$ expanded). Takiyama et al. (1997), however, using the same approach as Grewal et al. (1999), reported SRD favouring the expanded alleles (61\%). In family studies, Ikeuchi et al.(1996) and Iughetti et al.(1998) identified SRD favouring the expanded alleles in paternal transmissions (73\% and 59\%, respectively), whereas Riess et al. (1997) observed the same phenomenon but in maternal transmissions (72\%). Issues related to criteria for family selection in these studies could at least partially explain the conflicting results. If families were recruited for linkage or other genetic studies, as suggested by Grewal et al. (1999), the tendency in favour of transmission of expanded alleles could be highly influenced by a sampling bias. Our work provides the analysis of complete sibships, comprising 330 transmissions, with a mean $\sim 5$ offspring per transmitter (minimum 1; maximum 14) and a range of 0-7 affected and 0-11 unaffected offspring. Moreover, to our knowledge, this is the first clinical study that has taken into consideration the

Table 2 Frequency of transmission of normal and expanded alleles by Machado-Joseph disease patients

\begin{tabular}{lccclll}
\hline Parental origin & \multicolumn{2}{l}{ Allele transmitted } & \multirow{2}{*}{$\begin{array}{l}\chi^{2} \text { assuming } 1: 1 \\
\text { segregation }\end{array}$} & $P\left(\chi^{2}\right)$ \\
\cline { 2 - 4 } & Normal & Expanded & Total & \\
\hline Maternal & 88 & 68 & 156 & 2.564 & 0.109 \\
Paternal & 88 & 86 & 174 & 0.023 & 0.879 \\
Total & 176 & 154 & 330 & 0.982 & 0.322 \\
\hline
\end{tabular}


residual risk status for asymptomatic individuals. Data obtained in this study does not support the existence of SRD in favour of expanded alleles. Furthermore, a tendency for a preferential transmission of normal alleles is shown, being in agreement with what was described for normal families of Azorean origin (Bettencourt et al. 2008) for whom SRD in favour of the smaller normal alleles is reported. Thus, our results do not support SRD as a mechanism on the basis of the high values of MJD prevalence.

Acknowledgments This work was supported by "Projecto Regional Integrado-DMJ (PRI-DMJ)" (funded by Regional Government of the Azores). CB (SFRH/BD/21875/2005) is a recipient of a Ph.D. grant, and CS (SFRH/BPD/20944/2004) is a postdoctoral fellow from "Fundação para a Ciência e a Tecnologia" (FCT).

\section{References}

Abade A, Santos C, Lima M, Freire-Gonçalves A, Carvalho S, Coutinho P (2000) Reproductive success in families with Machado-Joseph disease from the center of Portugal. In: Varela TA (ed) Investigaciones en Biodiversidad Humana. Universidade de Santiago de Compostela, Santiago de Compostela

Bettencourt C, Santos C, Kay T, Silva C, Vasconcelos J, Santos J, Maciel P, Lima M (2005) Clinical presentation and size of the CAG tract in Machado-Joseph disease patients from the Azores Islands (Portugal). Açoreana 10(2):311-318

Bettencourt C, Fialho RN, Santos C, Montiel R, Bruges-Armas J, Maciel P, Lima M (2008) Segregation distortion of wild-type alleles at the Machado-Joseph disease locus: a study in normal families from the Azores islands (Portugal). J Hum Genet 53(4):333-339

Cagnoli C, Mariotti C, Taroni F, Seri M, Brussino A, Michielotto C, Grisoli M, Di Bella D, Migone N, Gellera C, Di Donato S, Brusco A (2006) SCA28, a novel form of autosomal dominant cerebellar ataxia on chromosome 18p11.22-q11.2. Brain 129:235-242

Coutinho P (1992) Doença de Machado-Joseph: Tentativa de Definição, PhD Dissertation, Instituto de Ciências Biomédicas Abel Salazar, Porto

Coutinho P, Andrade C (1978) Autosomal dominant system degeneration in Portuguese families of the Azores Islands. Neurology 28:703-709

Drüsedau M, Dreesen JC, De Die-Smulders C, Hardy K, Bras M, Dumoulin JC, Evers JL, Smeets HJ, Geraedts JP, Herbergs J (2004) Preimplantation genetic diagnosis of spinocerebellar ataxia 3 by $(\mathrm{CAG})(n)$ repeat detection. Mol Hum Reprod 10:71-75

Grewal RP, Cancel G, Leeflang EP, Dürr A, McPeek MS, Draghinas D, Yao X, Stevanin G, Alnot MO, Brice A, Arnheim N (1999) French Machado-Joseph disease patients do not exhibit gametic segregation distortion: a sperm typing analysis. Hum Mol Genet 8:1779-1784

Ichikawa Y, Goto J, Hattori M, Toyoda A, Ishii K, Jeong SY, Hashida H, Masuda N, Ogata K, Kasai F, Hirai M, Maciel P, Rouleau GA, Sakaki Y, Kanazawa I (2001) The genomic structure and expression of MJD, the Machado-Joseph disease gene. J Hum Genet 46:413-422

Ikeuchi T, Igarashi S, Takiyama Y, Onodera O, Oyake M, Takano H, Koide R, Tanaka H, Tsuji S (1996) Non-Mendelian transmission in dentatorubral-pallidoluysian atrophy and Machado-Joseph disease: the mutant allele is preferentially transmitted in male meiosis. Am J Hum Genet 58:730-733
Iughetti P, Otto PA, Zatz M, Passos Bueno MR, Marie SK (1998) Different behavior in the paternally vs. maternally inherited mutated allele in Brazilian Machado-Joseph (MJD1) families. Am J Med Genet 77:246-248

Kawaguchi Y, Okamoto T, Taniwaki M, Aizawa M, Inoue M, Katayama S, Kawakami H, Nakamura S, Nishimura M, Akiguchi I, Kimura J, Narumiya S, Kakizuka A (1994) CAG expansions in a novel gene for Machado-Joseph disease at chromosome 14q32.1. Nat Genet 8:221-228

Lima M (1996) Machado-Joseph disease in the Azores: an epidemiological, genealogical and genetic study. PhD dissertation (in Portuguese). University of the Azores, Ponta Delgada

Lima M, Mayer FM, Coutinho P, Abade A (1998) Origins of a mutation: population genetics of Machado-Joseph disease in the Azores (Portugal). Hum Biol 70:1011-1023

Lima M, Smith MT, Silva C, Abade A, Mayer FM, Coutinho P (2001) Natural selection at the MJD locus: phenotypic diversity, survival and fertility among Machado-Joseph disease patients from the Azores. J Biosoc Sci 33:361-373

Maciel P, Costa MC, Ferro A, Rousseau M, Santos CS, Gaspar C, Barros J, Rouleau GA, Coutinho P, Sequeiros J (2001) Improvement in the molecular diagnosis of Machado-Joseph disease. Arch Neurol 58:1821-1827

Nakano KK, Dawson DM, Spence A (1972) Machado disease. A hereditary ataxia in Portuguese emigrants to Massachusetts. Neurology 22:49-55

Riess O, Epplen JT, Amoiridis G, Przuntek H, Schols L (1997) Transmission distortion of the mutant alleles in spinocerebellar ataxia. Hum Genet 99:282-284

Santos C, Abade A, Lima M, Freire-Gonçalves A, Carvalho S, Coutinho P (2000) Machado-Joseph disease in Portugal: the beginning of a long 'puzzle'. In: Varela TA (ed) Investigaciones en Biodiversidad Humana. Universidade de Santiago de Compostela, Santiago de Compostela

Sequeiros J (1993) Machado-Joseph disease: epidemiology, genetics and genetic epidemiology. In: Lechtenberg R (ed) Handbook of cerebellar diseases. Marcel Dekker, New York

Sequeiros J (1996) General protocol of the national program of predictive testing and genetic counselling in Machado-Joseph disease. In: Sequeiros J (ed) Predictive testing in MachadoJoseph disease (in Portuguese). UnIGENe-IBMC, Porto

Sequeiros J, Maciel P, Taborda F, Lêdo S, Rocha JC, Lopes A, Reto F, Fortuna AM, Rousseau M, Fleming M, Coutinho P, Rouleau GA, Jorge CS (1998) Prenatal diagnosis of Machado-Joseph disease by direct mutation analysis. Prena Diagn 18:611-617

SPSS Inc. (2006) SPSS for Windows, Release 15.0. SPSS Inc., Chicago

Takiyama Y, Nishizawa M, Tanaka H, Kawashima S, Sakamoto H, Karube Y, Shimazaki H, Soutome M, Endo K, Ohta S, Kagawa Y, Kanazawa I, Mizuno Y, Yoshida M, Yuasa T, Horikawa Y, Oyanagi K, Nagai H, Kondo T, Inuzuka T, Onodera O, Tsuji S (1993) The gene for Machado-Joseph disease maps to human chromosome 14q. Nat Genet 4:300-304

Takiyama Y, Sakoe K, Soutome M, Namekawa M, Ogawa T, Nakano I, Igarashi S, Oyake M, Tanaka H, Tsuji S, Nishizawa M (1997) Single sperm analysis of the CAG repeats in the gene for Machado-Joseph disease (MJD1): evidence for non-Mendelian transmission of the MJD1 gene and for the effect of the intragenic CGG/GGG polymorphism on the intergenerational instability. Hum Mol Genet 6(7):1063-1068

Woods BT, Schaumburg HH (1972) Nigro-spino-dentatal degeneration with nuclear ophthalmoplegia. A unique and partially treatable clinico-pathological entity. J Neurol Sci 17:149-166

Young ID (2007) Introduction to risk calculation in genetic counselling, 3rd edn. Oxford University Press, New York 